\title{
Potential Binding Sites of Toluidine Blue $O$ in Gram- Positive Bacterial Membrane Wall Teichoic Acid: Modeling Approach
}

\author{
Heba EISayed ElZorkany ${ }^{1 \mathbb{D}}$, Hisham A. Elshoky ${ }^{2 \mathbb{D}}$, Amina Omar ${ }^{3 \mathbb{C}}$, Medhat Ibrahim ${ }^{4, * \mathbb{C}}$ \\ 1 Nanotechnology and Advanced Materials Central Lab, Agricultural Research Center, Giza, Egypt; \\ heba.elzorkany@gmail.com (H.E.E.); \\ 2 Nanotechnology and Advanced Materials Central Lab, Agricultural Research Center; heshamalshoky@sci.cu.edu.eg \\ (H.A.E); \\ 3 Physics Department, Biophysics Branch, Faculty of Science, Ain Shams University, 11566, Cairo, Egypt; \\ a.omar9@ hotmail.com (A.O.); \\ 4 Molecular Spectroscopy and Modeling Unit, Spectroscopy Department, National Research Centre, 33 El-Bohouth St., \\ 12622 Dokki, Giza, Egypt; ma.khalek@nrc.sci.eg (M.I.); \\ * Correspondence: ma.khalek@nrc.sci.eg;
}

Scopus Author ID 8641587100

Received: 6.12.2020; Revised: 30.12.2020; Accepted: 2.01.2021; Published: 4.01.2021

\begin{abstract}
Photodynamic therapy (PDT) introduces a promising alternative to traditional antibiotics. However, the mechanism of binding the photosensitizers (PSs) to the bacterial cells and their specific cellular localization is not fully understood. The importance of understanding the mechanism of binding comes from two reasons. The first one is: the binding site is expected to be the place of the first damage of the photodynamic effect. This helps in understanding the mechanism of action. This moves us forward to the second reason, which is, by developing our understanding of the PDT mechanism, we can know and avoid the potential resistance pathways by bacteria. This study chooses one of the promising photosensitizers, toluidine blue $\mathrm{O}$ (TBO), to study its binding with a single membrane component, teichoic acid. Teichoic acid (TA) is a potential binding target in the Gram-positive bacterial membrane. By applying to model using the semi-empirical SP3 method to find out the potential binding interaction between single TA and single TBO molecules, we find that the nitrogen atom in the middle ring of the TBO molecule is the most probable to be the root of interaction with the TA molecule. While $\mathrm{OH}$ groups in the TA structure are the most likely site of interaction with TBO.
\end{abstract}

Keywords: teichoic acid; toluidine blue O; photodynamic therapy; multi-drug resistance; dye-cell interaction.

(C) 2020 by the authors. This article is an open-access article distributed under the terms and conditions of the Creative Commons Attribution (CC BY) license (https://creativecommons.org/licenses/by/4.0/).

\section{Introduction}

Discovering penicillin by Fleming in 1928 [1] was a great victory over the bacterial threads that save millions of humans. Unfortunately, after years of excessive, random misusing and overusing antibiotics, many bacteria have developed multi-drug resistance (MDR) against most of our antibiotics [2]. After the prolonged use of a broad spectrum of antibiotics, MDR bacteria cause difficult-to-treat or even untreatable infections with conventional antimicrobials [3]. MDR is a growing problem that affects the health sector worldwide. International organizations as World Health Organization (WHO), the European Centre for Disease Prevention and Control (ECDC), and the US Centers for Disease Control and Prevention 
(CDC) are considering infections caused by MDR bacteria as an emergent global disease and a major public health problem [4]. Recently, bacteria achieved some victories in this battle, so that we must develop new treatment options and alternative antimicrobial therapies. Photodynamic therapy (PDT) introduces a promising alternative to traditional antibiotics.

PDT depends on three elements light, oxygen, and photosensitizer (PS). By irradiating the PS by light, with the proper wavelength, in the presence of oxygen, the stimulated PS produces singlet oxygen or reacts with the surrounding molecules to produce free radicals species, which, in turn, damages the targeted cells [5]. Photosensitization mediated cell damage has many important medical applications, especially in cancer therapy and photodynamic microbial inactivation (PDI). One of the very promising photosensitizers is toluidine blue $\mathrm{O}$ (TBO). TBO (2-methyl-3-dimethylamino-7-amino-phenothiazin-5-ium), a cationic phenothiazinium metachromatic dye, has a high affinity to acidic tissue components [6]. TBO is commonly used in oral antimicrobial PDT as a photosensitizing agent due to its high selectivity in bacteria destruction [7]. Moreover, TBO is a very promising drug for the detection and therapy of oral squamous cell carcinoma and general oral cavity [7]. While the uptake of cationic PSs is mediated by electrostatic interactions and self-promoted uptake pathways [8]. However, the PS's mechanism to the cells and its specific cellular localization is not yet fully understood. Many efforts had been made to reveal the mechanisms of TBO cell binding. Some were in the context of chemical bonds [9]. But many literatures nominate wall teichoic acid (TA) as a potential binding site for cationic PSs in Gram-positive (G+) bacterial cell wall [911]. Wall teichoic acid (TA) is an anionic glycopolymer that functionalizes the peptidoglycan layers of many $\mathrm{G}+$ bacteria [12]. TA has important bacterial physiology functions in colonization, cell shape determination, cell division regulation, and infection. TA has recently attracted major attention as a target structure for novel anti-infective strategies and antibiotics $[13,14]$. TA governs the interaction of many substances with Gram-positive bacterial cell walls as nanoparticles [15] and dyes. TA exhibits variable structures between bacterial species. Usually, it contains phosphate and alditols [16]. Computational modeling tools is a very promising and successful tool. Although various biological and chemical experimental assays for drug-target interaction identification are available, they are extremely costly, timeconsuming. To face this challenge, various computational modeling introduces a new high efficient tool to predict potential drug-target associations [17]. To achieve a satisfactory assignment of the TBO/TA interaction was assigned using the semi-empirical method. Computational methods show effective applications in many research areas, whereas the experimental tools are limited or unavailable [18-20]. It covers a wide area of applications such as environmental [21-23], biological [24-26], polymers science [27-30] as well as emerging materials [31-33]. Semi-empirical methods provide information on primary calculations of different chemical properties with reasonably good results [34]. The simplified P3 theory, or SP3 for short, is believed to be more compatible than diffusion theory in advanced reactors, mini cores, and other complicated whole core three-dimensional transport calculations at pin level resolutions. At locations in the core with high flux gradient, such as material boundaries, the SP3 has high precision due to the use of the higher-order Pn scattering library [35]. The SP3 method, as expected, can provide accuracy improvement compared with the commonly used diffusion method. Besides, implementing the SP3 equations into the diffusion code is not difficult because of the similar structure of the SP3 and diffusion equations [36].

In an earlier study, we demonstrated the photodynamic inactivation (PDI) of Escherichia coli and Bacillus cereus by TBO and red laser experimentally [37]. In the current 
study, we try to decipher the potential binding ways between TBO and TA, G+ bacterial cell wall component, by using computational modeling.

\section{Materials and Methods}

To find out the potential binding interaction between single Teichoic acid (TA) and single toluidine blue $\mathrm{O}$ (TBO) molecules, the TA structure was drawn by GaussView 5.0.9 software (Gaussian, Inc., Wallingford, CT) (Figure 1A) [38]. Also, the TBO structure was drawn by Gauss View 5.0.9 software (Figure 1B) [7]. The geometries of individual TA and TBO were optimized using Gaussian 03 Revision-B.05 (Gaussian, Inc., Wallingford, CT) by employing (Semi-empirical/Default Spin/PM3) method. Different binding interactions are suggested. The highest occupied molecular orbital (HOMO), lowest unoccupied molecular orbital LUMO, changes in the HOMO-LUMO energy $(\Delta \mathrm{E})$, dipole moment (TDM), and total energy (E) of TA, TBO, and the eight binding interaction of TBO and TA were calculated using Gaussian 09 [39] at Spectroscopy Department, National Research Centre, Egypt.

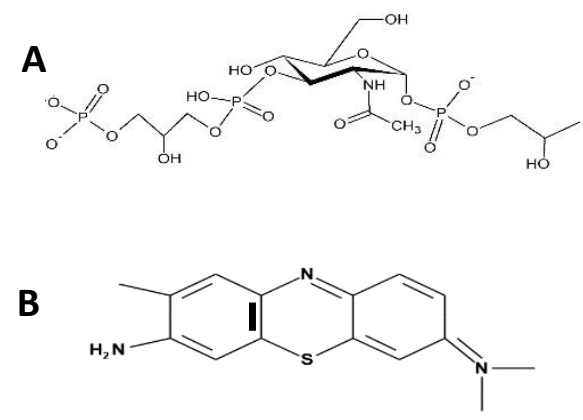

Figure 1. (A) and (B) illustrating the chemical structures of TA and TBO, respectively.

\section{Results and Discussion}

Figure 2 illustrates the structure, molecular electrostatic potential (MESP) maps, and HOMO-LUMO for TA and TBO. MESP map indicates the net electrostatic effect produced at that point by the total charge distribution (electron + nuclei) of the molecule.

A

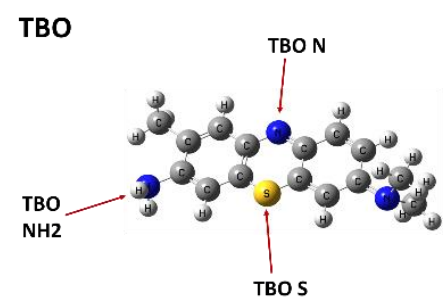

B

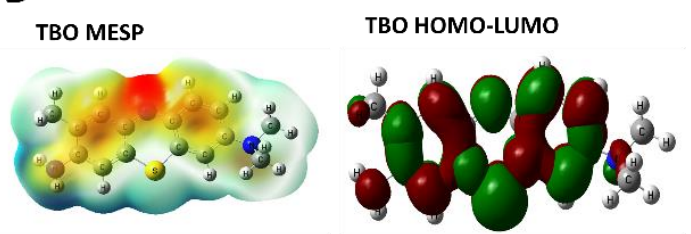

$A^{\prime} \quad$ TA

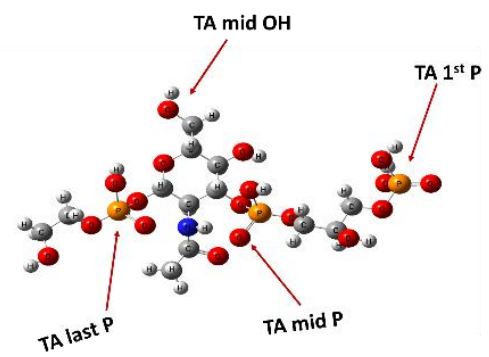

$\mathbf{B}^{\prime}$

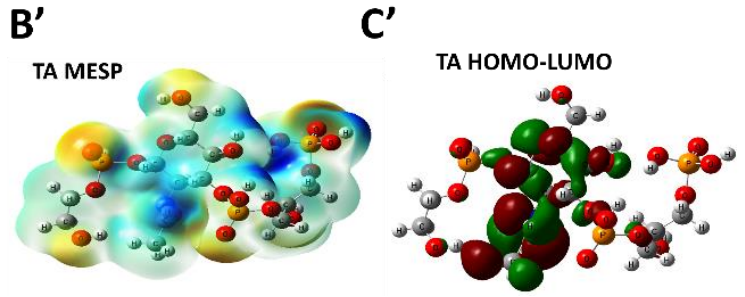

Figure 2. (A) and (A') illustrating the structure and the selected binding sites in TBO and TA, respectively; (B) and (B') the MESP of TBO and TA, respectively; (C) and (C') the HOMO-LUMO of TBO and TA, respectively. 
It correlates with charge-dipole, dipole-dipole, quadrupole-dipole, partial charges, and chemical reactivity of the molecule that leads to the understanding of the interaction with biological molecules [40]. The molecular electrostatic potential values are clarified at the surface by gradient colors, whereas red represents regions of the highest negative electrostatic potential (electrophilic attack), and blue shows regions of the highest positive electrostatic potential (nucleophilic attack). So, the MESP negativity in descending order is red < orange < yellow < green < blue $[41,42]$.

Therefore, twelve hypothesized binding sites were selected in both TBO and TA according to the obtained MESP, by alternative exchanges of the different potential binding sites in both structures. Subsequently, the suggested structures were calculated by the semiempirical PM3 basis set. Only eight binding interactions were succeeded according to the applied method. The selected binding sites, as illustrated in figure $2 \mathrm{~A}, \mathrm{~A}$ '.

\subsection{Molecular electrostatic potential of unbound TBO.}

The unbound TBO MESP surface map (Figure 2B) shows that the structure has a dense red color surrounding the nitrogen atom in the middle ring. This is attributed to the high electronegativity nature of the nitrogen atom. It possesses two lone pairs of electrons that have the ability to draw the electrons from other carbon and hydrogen atoms in the ring. Then, come in the second order of electronegativity, the terminal amine group, as it shows orange color. Meanwhile, the triple ring structure of TBO has a predominant negative backbone, which is surrounded by pale blue color around the rings due to hydrogen atoms that possess positive nature. Moreover, only one sulfur atom in the TBO structure shows a pale blue color related to its similar electronegativity to $\mathrm{C}$ and its additional valence electrons [43]. Thus it would be expected that nitrogen will be the most reactive site for an electrophilic attack in the TBO molecules, while sulfur will be the most nucleophilic reactive site [42]. According to the stated results, three potential binding sites in the TBO structure were selected.

\subsection{Molecular electrostatic potential of unbound TA.}

The calculated MESP surface map for TA (Figure 2B') shows that the negative regions are electrophilic. These are mainly over the phosphoryl groups. The deep blue positive regions were mainly the hydroxyl groups in the TA molecule. Thus it would be expected that phosphoryl groups will be the most reactive site for electrophilic interaction site, while the two hydroxyl groups will be the most nucleophilic interaction site in the TA molecule [42]. The red surface color represents the high negative sites in the structure. The surface color around phosphoryl groups shows the TA molecule's high negatively, followed by the surface map's orange color around the $\mathrm{OH}$ group along the entire TA molecule. In comparison, the blue color covers some places in the TA's surface map around some hydrogen atoms. According to the stated results, four potential binding sites in the TA structure were selected.

The succeeded eight binding interactions are illustrated in Figure 3. They were named as TA mid P- TBO S, TA mid P- TBO N, TA mid P- TBO NH 2 , TA last P-TBO NH 2 , TA mid OH- TBO N, TA mid OH- TBO N, TA mid OH- TBO S, and TA $1{ }^{\text {st }} \mathrm{P}-\mathrm{TBO} \mathrm{N}$. While the MESP, and HOMO-LUMO of every structure are illustrated in figures 4-11. 


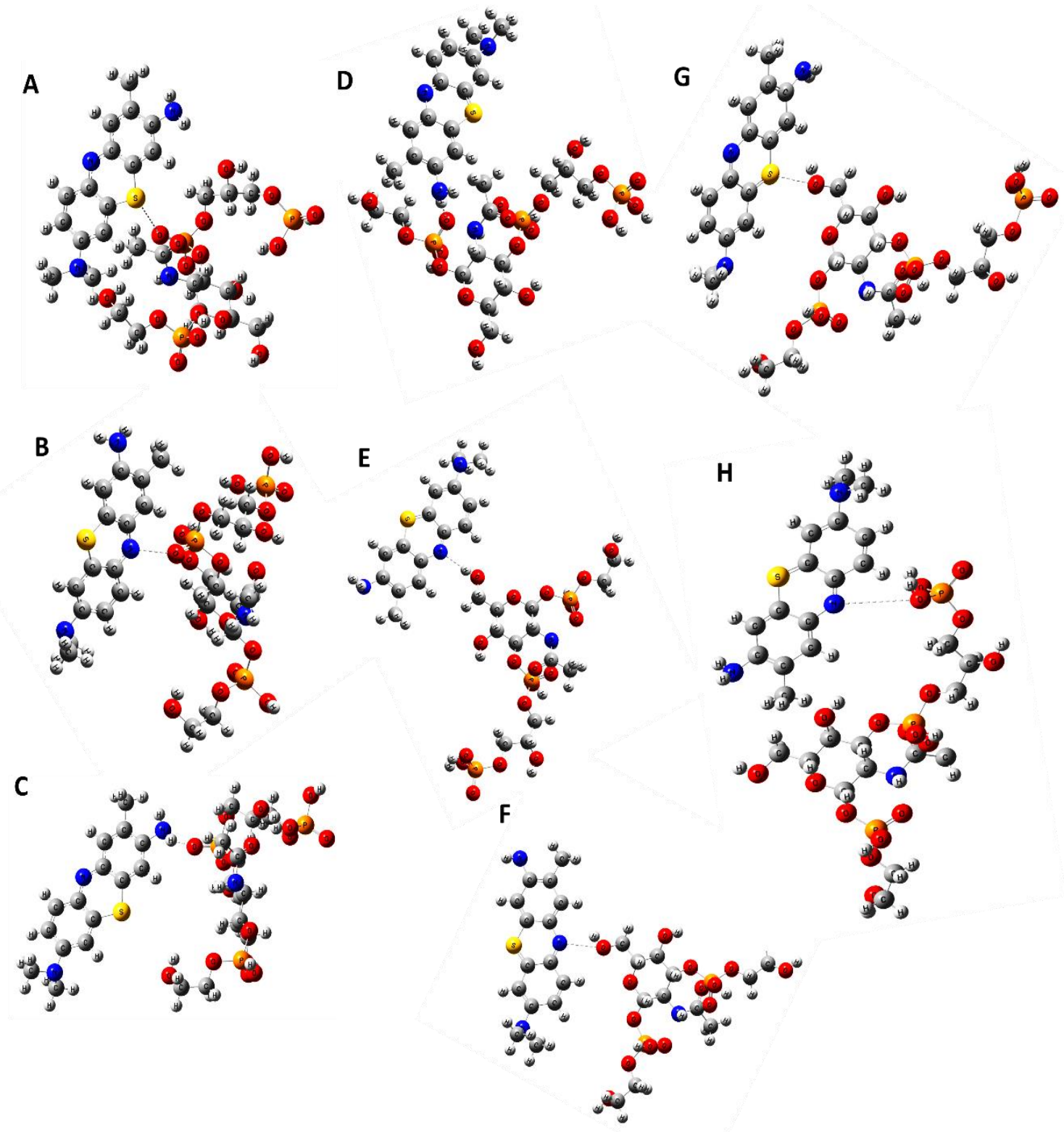

Figure 3. Potential binding sites of TA and TBO as (A) TA mid P- TBO S; (B)TA mid P- TBO N; (C) TA mid P- TBO NH $2 ;$ (D) TA last P-TBO $\mathrm{NH}_{2}$ (E) TA mid OH- TBO N; (F) TA mid OH- TBO N; (G) TA mid $\mathrm{OH}-\mathrm{TBO} \mathrm{S} ;(\mathbf{H})$ TA $1^{\text {st }} \mathrm{OH}-\mathrm{TBO} \mathrm{N}$.

\subsection{Molecular electrostatic potential of hypothesized interacted TA-TBO.}

\subsubsection{TA mid P- TBO S.}

This prospect depends on the interaction between the sulfur atom in the TBO phenothiazine molecule (TBO S) and the middle phosphoryl group of TA molecule backbone (TA mid P) (TA mid P- TBO S) (Figure 4), has appeared in the MESP map of unbound TBO, the sulfur atom was surrounded by a blue cloud that indicates the positivity of this atom, while the oxygen atom in the unbound TA MESP map showed a clear orange color that indicates its negativity. By studying TBO-TA interaction probability through TA mid P- TBO S binding interaction, the MESP map shows the very pale yellow color of the same phosphoryl group in the TA molecule. After the interaction, the phenothiazine $S$ show a light blue color. This indicates that after an interaction, both molecules show charge redistribution. Nonetheless, the $\mathrm{N}$ atom in the middle ring of TBO still red that refers to its high activity. 


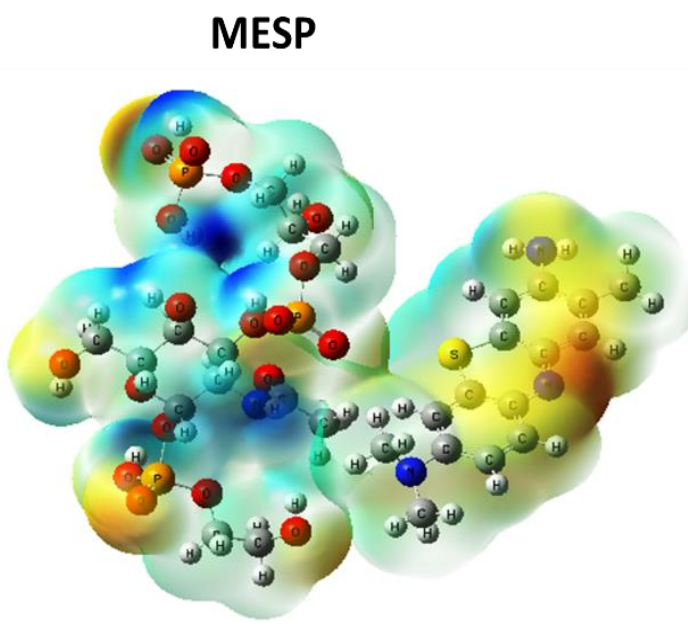

HOMO-LUMO

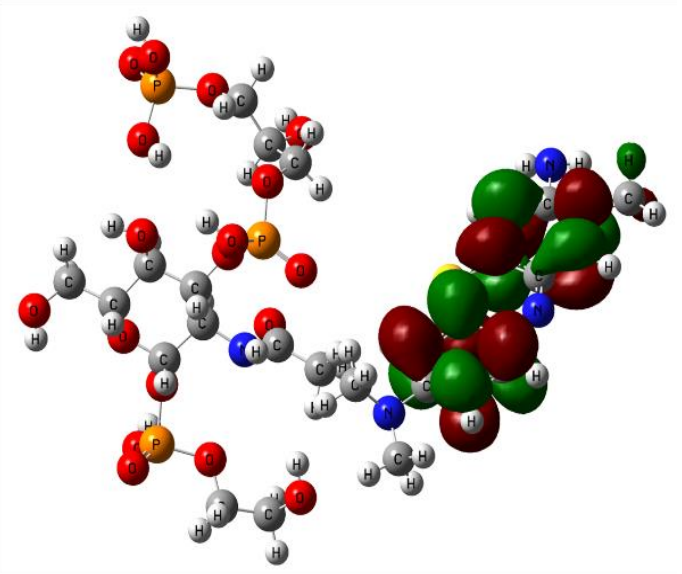

Figure 4. TA mid P- TBO S MESP, and HOMO-LUMO.

\subsubsection{TA mid OH- TBO S.}

This prospect depends on the interaction between the sulfur atom in the TBO phenothiazine molecule (TBO S) and the oxygen atom of the middle $\mathrm{OH}$ group of the TA molecule (TA mid OH) (Figure 5), as appeared in the MESP map of the unbound TA the oxygen showed a clear orange color that indicates its negativity. By studying TBO-TA conjugation probability through TA mid $\mathrm{OH}-\mathrm{TBO} \mathrm{S}$ binding interaction, the resulted MESP map shows charge redistribution compared to the unbound TBO and TA molecules. The very pale blue color of the binding site after conjugation indicates the vanishing of extreme positive and negative sites. While the $\mathrm{N}$ atom in the middle ring of TBO possesses slightly high negativity, this could be due to the unconjugated lone pair of electrons around the nitrogen atom $[44,45]$.

MESP

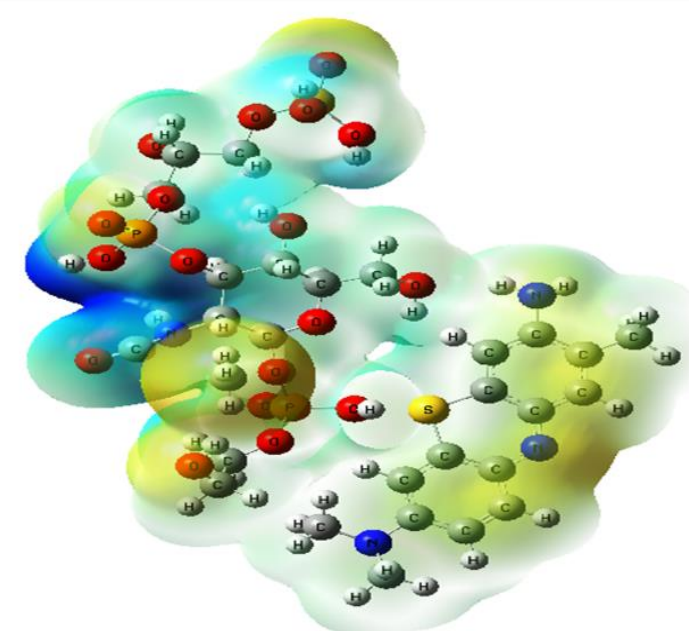

\section{HOMO-LUMO}

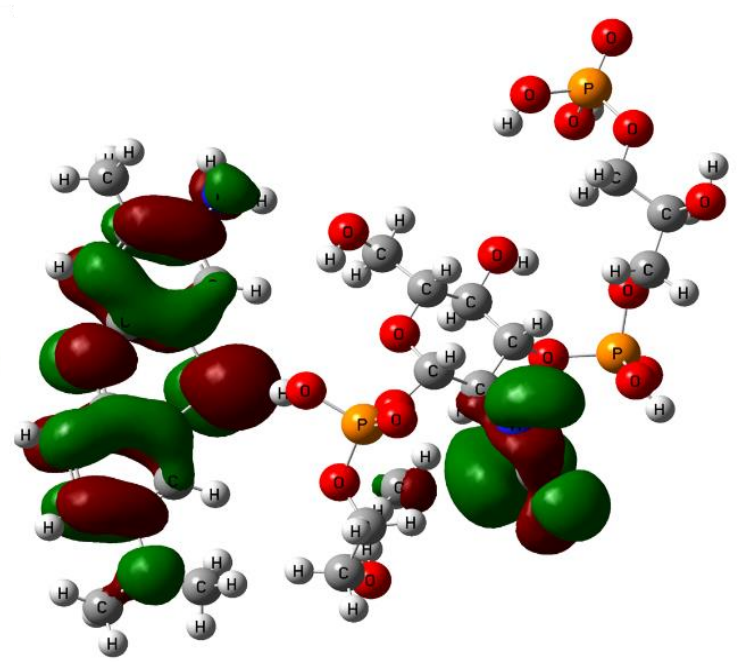

Figure 5. TA mid OH- TBO S MESP and HOMO-LUMO.

\subsubsection{TA mid P- $\mathrm{TBO} \mathrm{NH}_{2}$.}

In this scenario, the interaction is between the terminal amine group in the TBO molecule (TBO $\mathrm{NH}_{2}$ ) and the TA mid P (TA mid P- TBO NH 2 ) (Figure 6). The bound TA show distinct electron-rich regions (orange) at the phosphoryl groups, while the $\mathrm{C}-\mathrm{H}$ hydrogen 
atoms regions in the rest of the TA molecule was found to be strong and slightly electrondeficient (blue and pale blue, respectively). Concomitantly, the bounded TBO molecule shows lower electronegativity compared to the unbound molecule. This could be due to the attraction of the electrons by the oxygen atoms in TA phosphoryl groups. While the $\mathrm{N}$ atom in the middle ring of the bound TBO still high negative, that refers to its high activity and low electrostatic potential [40].

\section{MESP}

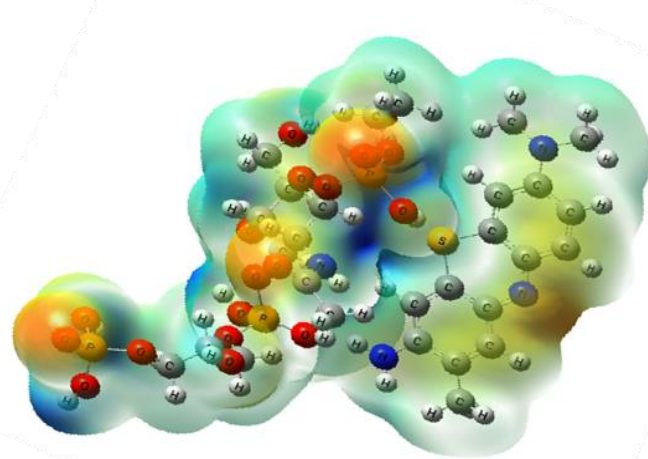

HOMO-LUMO

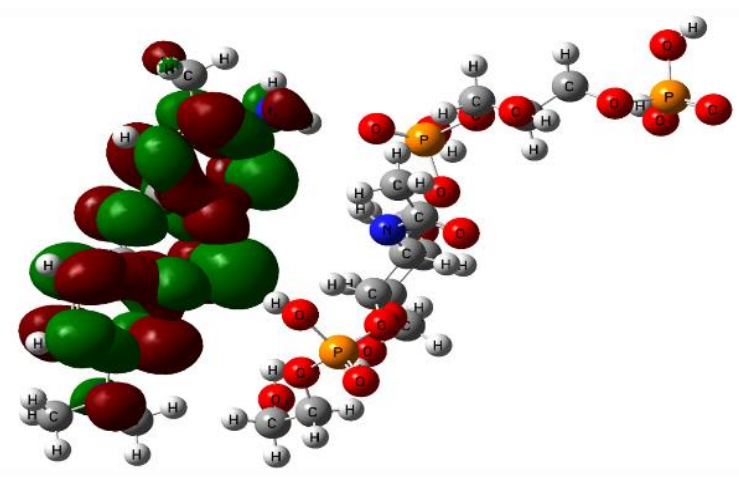

Figure 6. TA mid P- TBO $\mathrm{NH}_{2}$, MESP and HOMO-LUMO.

\subsubsection{TA last $\mathrm{P}-\mathrm{TBO} \mathrm{NH}_{2}$}

The current scenario study the interaction between $\mathrm{TBO} \mathrm{NH}_{2}$ and the last phosphoryl group of TA molecule (TA last $\mathrm{P}$ ) (TA last $\mathrm{P}-\mathrm{TBO} \mathrm{NH}_{2}$ ) (Figure 7). The bound TA show distinct electron-rich regions (red and orange) at the phosphoryl groups of TA, while regions around the rest of the TA molecule show the $\mathrm{C}-\mathrm{H}$ blue and pale blue colors. Concomitantly, the bounded TBO molecule shows lower electronegativity compared to the unbound molecule. This could be due to the attraction of the electrons by the phosphoryl groups in TA. While the $\mathrm{N}$ atom in the middle ring of the bound TBO still high negative that refers to its high activity and low electrostatic potential [40].

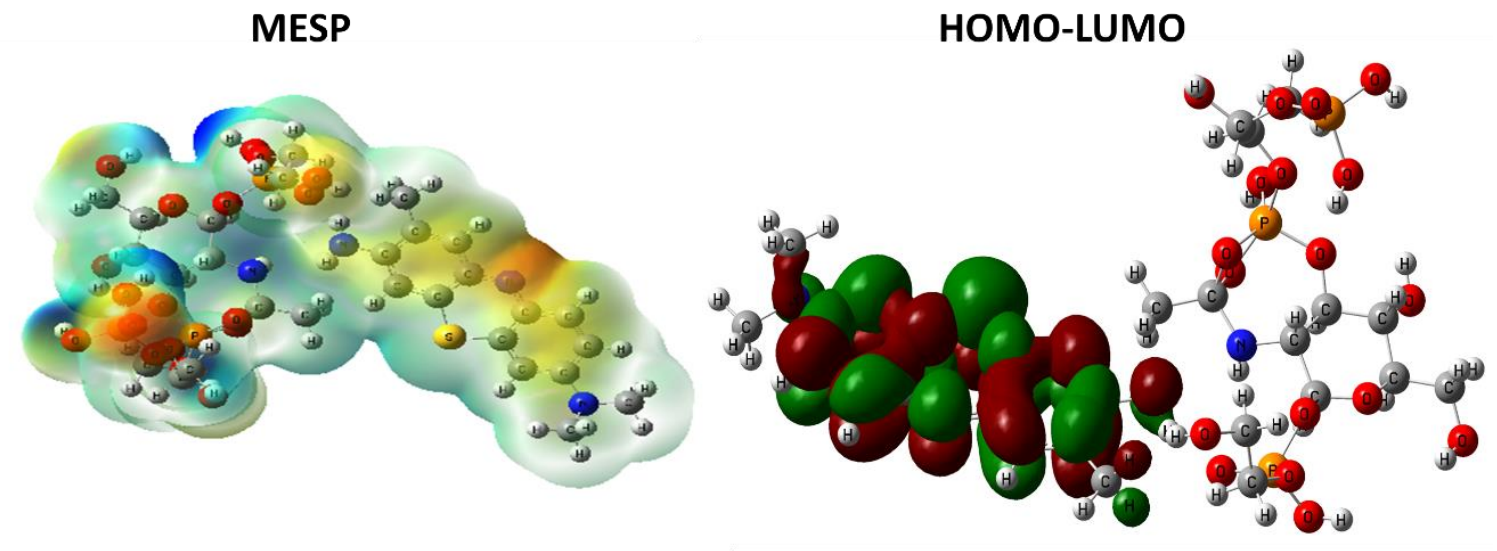

Figure 7. TA last $\mathrm{P}-\mathrm{TBO} \mathrm{NH}_{2}$ MESP and HOMO-LUMO.

\subsubsection{TA mid OH'-TBO N.}

This prospect explores the interaction between TBO $\mathrm{N}$ and the hydrogen atom in the last hydroxyl group of TA molecule (TA mid $\mathrm{OH}^{\prime}$ ) (TA mid $\mathrm{OH}^{-}$- TBO N) (fig. 8). As the nitrogen atom in the middle ring of TBO shows high negativity, it was worth studying the 
prospect of its interaction with the positive hydroxyl group of TA. Results show that the bound TA shows the as previous red/blue surface map. Meanwhile, the bounded TBO molecule shows lower electronegativity compared to the unbound molecule. This could be due to the attraction of the electrons by the oxygen atoms in TA phosphoryl groups. While the $\mathrm{N}$ atom in the middle ring loses its negativity, and the total TBO appears to have a neutral distribution of charges [40]. This could be explained as the lone pair of electrons of nitrogen could delocalize and conjugate with the TA mid $\mathrm{OH}^{`}$ [44].

MESP

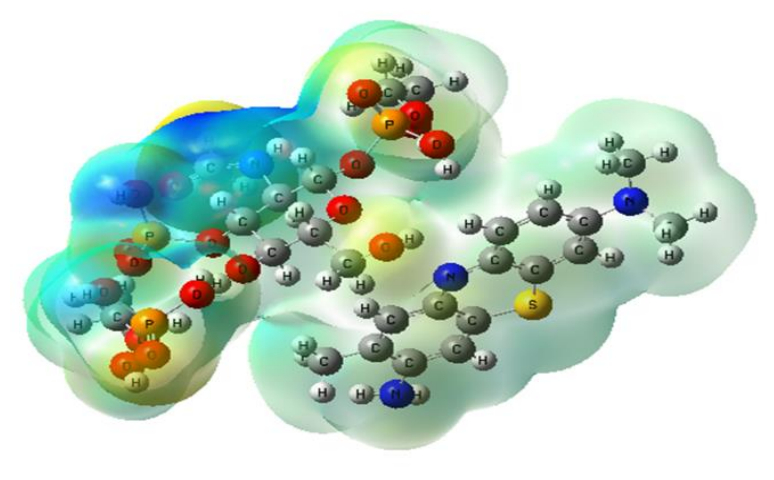

HOMO-LUMO

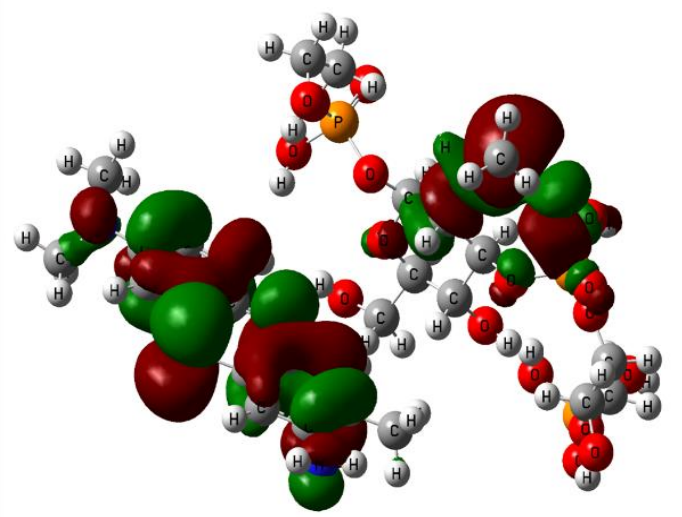

Figure 8. TA mid OH- TBO N MESP and HOMO-LUMO.

\subsubsection{TA mid O`H-TBO N.}

Because the hydroxyl group of the TA molecule was the more prospected binding site in the TA molecule, the interaction between the oxygen atom of the last hydroxyl group of the TA molecule (TA mid $\mathrm{O}^{`} \mathrm{H}$ ) and TBO N was studied (TA mid O`H- TBO N) (fig. 9). Results show that the bound TA shows its repeated MESP surface map. While the bounded TBO molecule shows lower electronegativity than the unbound molecule, this could be due to the attraction of the electrons by the phosphoryl groups in TA. Whereas, the $\mathrm{N}$ atom in the middle ring loses its negativity.

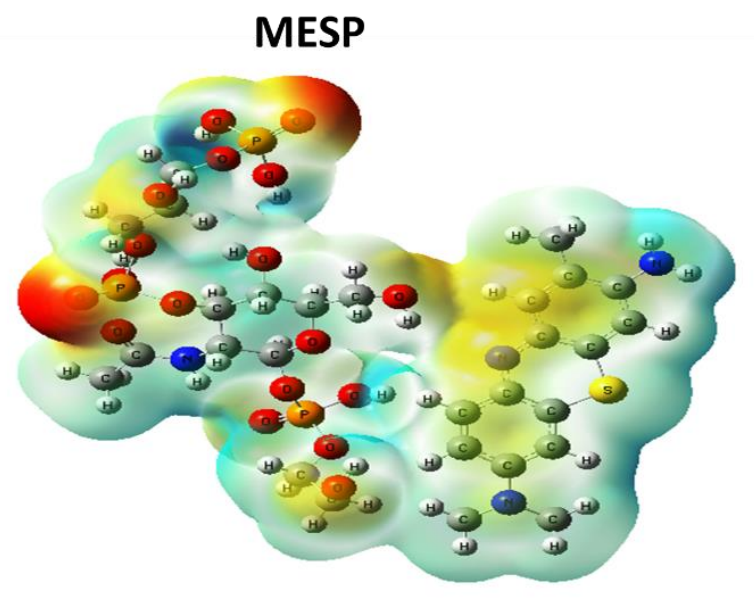

\section{HOMO-LUMO}

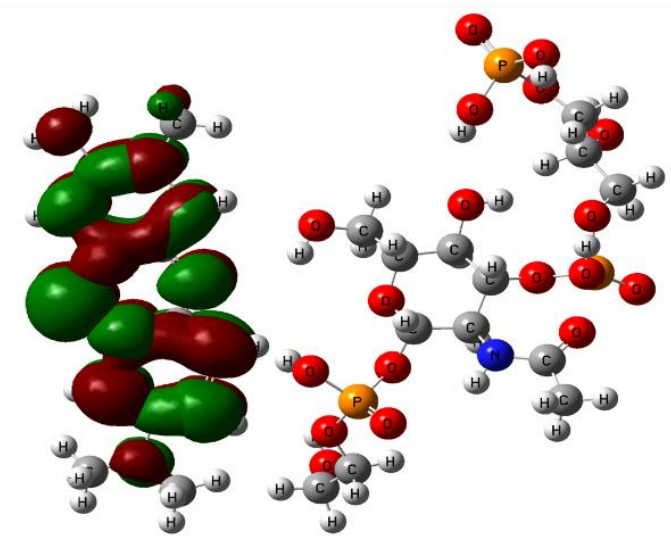

Figure 9. TA mid O`H- TBO N MESP and HOMO-LUMO.

\subsubsection{TA mid P-TBO N.}

The interaction between TBO $\mathrm{N}$ and the middle phosphoryl group of TA molecule (TA mid P) (TA mid P- TBO N) is illustrated in figure 10. The study of the interaction prospect of the TBO N with TA mid P shows that the bound TA shows the same MESP pattern. While, the 
bounded TBO show approximately the same electronegativity compared to the unbound molecule. Moreover, the $\mathrm{N}$ atom in the middle ring keeps its high negativity. This could be due to the equal electronegativity of both atoms TBO N and TA mid P, keeping the electrons in the middle distance between both atoms.

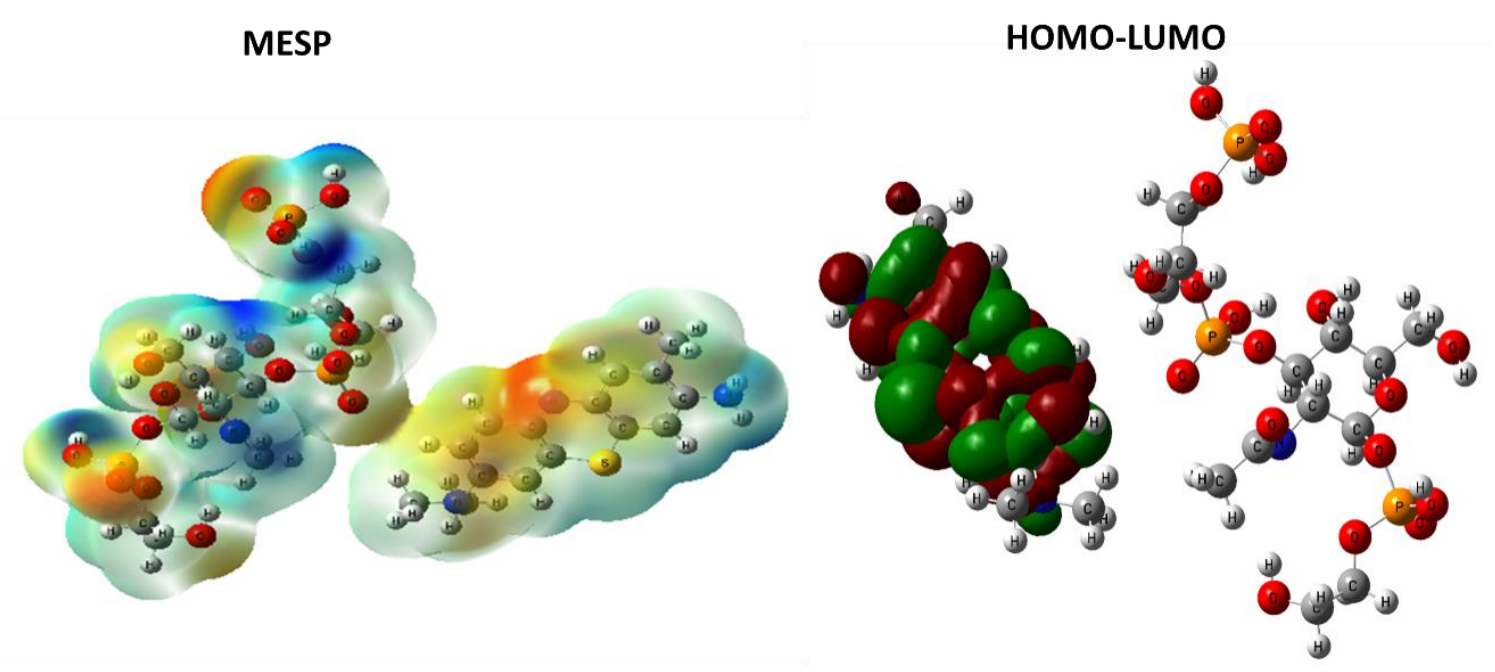

Figure 10. TA mid P- TBO N M ESP, and HOMO-LUMO.

\subsubsection{TA $1^{\text {st }} \mathrm{P}-\mathrm{TBO} \mathrm{N}$.}

In this hypothesize scenario the TBO $\mathrm{N}$ interacts with the first terminal phosphoryl group of TA molecule (TA $\left.1^{\text {st }} \mathrm{P}\right)\left(\mathrm{TA} 1^{\text {st }} \mathrm{P}-\mathrm{TBO} \mathrm{N}\right.$ ) (Figure 11). The interaction prospect shows that the bound TA shows yellow color at the phosphoryl groups, while regions around the rest of the TA molecule keep its blue and pale blue colors. On the other hand, the whole TBO molecule, including the $\mathrm{N}$ atom in the middle ring, shows charge redistribution. Nevertheless, middle $\mathrm{N}$ still slightly high electronegative the thing that depicts its activity. On the other hand, it's noted that the bound molecule loses the deep red color; instead of that, orange and yellow colors appeared that depicts relatively lower negativity compared to the unbound TBO molecule.

MESP

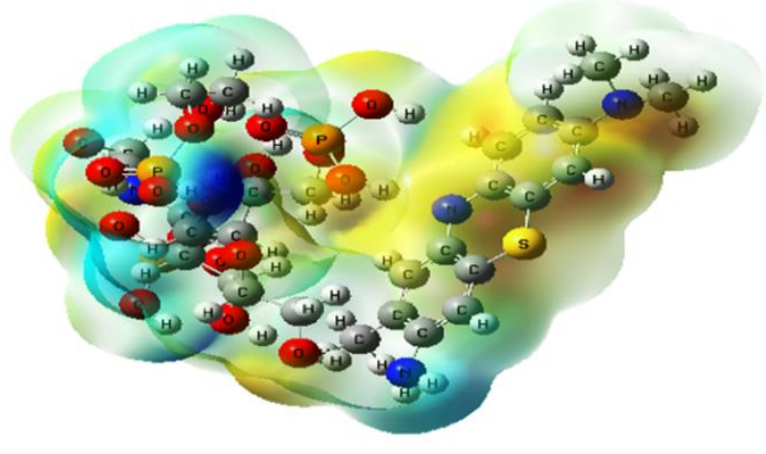

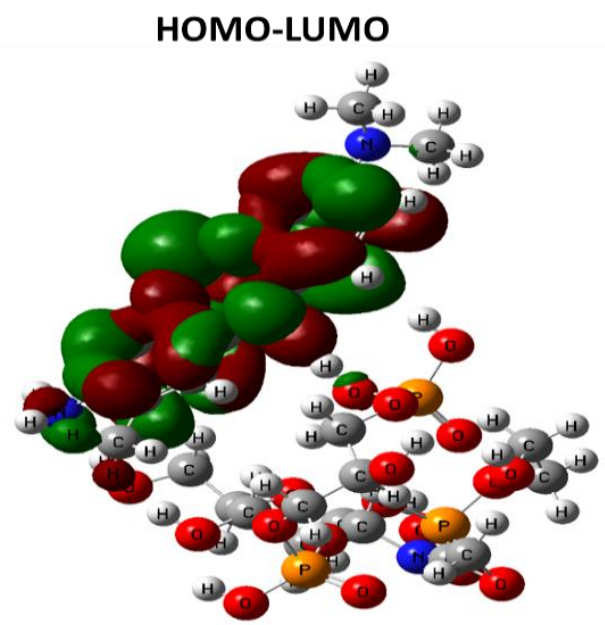

Figure 11. TA $1^{\text {st }} \mathrm{P}-\mathrm{TBO} \mathrm{N}$ MESP and HOMO-LUMO.

\subsection{HOMO-LUMO calculations.}

The HOMO energy and the LUMO energy reflect the total electron densities on a structure, where they both are the main orbits that take part in chemical stability $[45,46]$. The energy gap reflects the chemical activity of the molecules. The lower HOMO-LUMO energy 
gap explained the eventual charge transfer interactions within the molecules [41]. Whereas the HOMO-LUMO energy gap is a significant stability index, the visualization of HOMO-LUMO gap of TA, TBO, and all succeeded binding interactions are shown in Figures 2 C, C', and 411 , respectively.

Moreover, Table (1) lists the summary of our data with the HOMO, LUMO, changes in the HOMO-LUMO energy $(\triangle \mathrm{E})$, dipole moment (TDM), and total energy of TA, TBO, and eight binding interaction of TBO and TA. From the listed results it was found that the calculated values of the total energy of all suggested structure take the ascending order as TA mid P- TBO $\mathrm{NH}_{2}<$ TA mid P- TBO S $<$ TA mid P- TBO N $<$ TA last P-TBO $\mathrm{NH}_{2}<$ TA mid O`H-TBO N< TA mid OH- TBO $\mathrm{S}<\mathrm{TA}$ mid $\mathrm{OH}-\mathrm{TBO} \mathrm{N}<\mathrm{TA} 1^{\text {st }} \mathrm{P}-\mathrm{TBO} \mathrm{N}$.

TBO and TA possess $\Delta \mathrm{E}$ of 0.00961 and $0.20275 \mathrm{eV}$, respectively. The $\Delta \mathrm{E}$ has changed significantly upon the binding of TA with TBO to take the ascending order TA $1^{\text {st }} \mathrm{OH}-\mathrm{TBO}$ $\mathrm{N}<$ TA mid $\mathrm{P}-\mathrm{TBO} \mathrm{NH}_{2}<$ TA mid $\mathrm{O}^{\prime} \mathrm{H}-\mathrm{TBO} \mathrm{N}<$ TA last $\mathrm{P}-\mathrm{TBO} \mathrm{NH}_{2}<\mathrm{TA}$ mid O- TBO $\mathrm{S}<$ TA mid $\mathrm{OH}-\mathrm{TBO} \mathrm{S}<\mathrm{TA}$ mid $\mathrm{OH}-\mathrm{TBO} \mathrm{N}<\mathrm{TA}$ mid $\mathrm{P}-\mathrm{TBO} \mathrm{N}$. This indicate that TA $1^{\text {st }} \mathrm{P}-$ TBO $\mathrm{N}$ is more reactive [47].

Table 1. the summary of our data with the HOMO, LUMO, $\triangle \mathrm{E}$, TDM, and Total E of TA, TBO, and eight binding interactions of TBO and TA.

\begin{tabular}{l|c|c|c|c|c}
\multicolumn{1}{c|}{ Structure } & $\mathbf{\Delta E}$ & HOMO & LUMO & TDM & Total E \\
\hline TBO & 0.00961 & -0.00943 & 0.00018 & 0.4871 & 0.09725612 \\
\hline TA & 0.20275 & -0.33022 & -0.12747 & 3.0301 & -1.59008845 \\
\hline TA mid P- TBO S & 0.05696 & -0.30312 & -0.24616 & 2.6428 & -1.49585732 \\
\hline TA mid OH- TBO S & 0.03664 & -0.28071 & -0.24407 & 1.2000 & -1.40079572 \\
\hline TA mid P- TBO NH2 & 0.07065 & -0.24441 & -0.17376 & 5.8642 & -1.49932667 \\
\hline TA last P-TBO NH2 & 0.05734 & -0.30369 & -0.24635 & 4.3930 & -1.48892547 \\
\hline TA mid OH- TBO N & 0.03422 & -0.28044 & -0.24622 & 4.2767 & -1.37849178 \\
\hline TA mid O`H-TBO N & 0.06935 & -0.24313 & -0.17378 & 9.1217 & -1.48429456 \\
\hline TA mid P- TBO N & 0.28943 & -0.32201 & -0.03258 & 13.2716 & -1.49306738 \\
\hline TA $1^{\text {st P-TBO N }}$ & 0.07897 & -0.25429 & -0.17532 & 15.3599 & -1.32672646
\end{tabular}

On the other hand, the TDM of TA and TBO were 0.4871 and -1.59008845 Debye, respectively. However, TA $1^{\text {st }} \mathrm{OH}-\mathrm{TBO} \mathrm{N}$ shows 15.3599 Debye which was the highest TDM amongst all calculated structures. This indicates that it has the highest polarizability. Hypothesized prospect TA mid OH- TBO N shows the lower $\Delta \mathrm{E}$, however, the TA $1^{\text {st }} \mathrm{OH}-$ TBO $\mathrm{N}$ shows the higher TDM. Ultimately depending on these results, the nitrogen atom in the middle ring of the TBO molecule is the most probable root of interaction with the TA molecule. While $\mathrm{OH}$ groups in the TA structure are the most probable root of interaction with TBO. This could be ascribed to the opposed electronegative nature between them. Since the nitrogen atom has a single lone pair of electrons with high reactivity, the hydroxyl groups in the TA structure. TBO is a fast stain. Its interaction with TA is believed to be weak interaction as donor-acceptor hydrogen bond and dipole-dipole interaction [48]. As part of the TA cell wall, it mainly accounted for the physical adsorption [49,50].

\section{Conclusions}

The TBO is a promising antibacterial photosensitizer. However, its interaction with membrane teichoic acid is still uncovered as far as we know. Based on our results, the nitrogen atom in the middle ring of the TBO molecule is the most likely site of interaction with the TA molecule. This could be due to the electronegative nature of the nitrogen atom that can possess high reactivity. These findings represent a step toward understanding the mechanism of antibacterial action. 


\section{Funding}

This research received no external funding

\section{Acknowledgments}

We acknowledge the support of Prof. Hanan Elhaes during the preparation of this work.

\section{Conflicts of Interest}

The authors declare no conflict of interest.

\section{References}

1. Gaynes, R. The Discovery of Penicillin-New Insights After More Than 75 Years of Clinical Use. Emerging Infectious Disease journal 2017, 23, 849, https://doi.org/10.3201/eid2305.161556.

2. Ammar, A.M.; Abdeen, E.E.; Abo-Shama, U.H.; Fekry, E.; Kotb Elmahallawy, E. Molecular characterization of virulence and antibiotic resistance genes among Salmonella serovars isolated from broilers in Egypt. Lett. Appl. Microbiol. 2019, 68, 188-195, https://doi.org/10.1111/lam.13106.

3. Frieri, M.; Kumar, K.; Boutin, A. Antibiotic resistance. Journal of Infection and Public Health 2017, 10, 369378, https://doi.org/10.1016/j.jiph.2016.08.007.

4. Roca, I.; Akova, M.; Baquero, F.; Carlet, J.; Cavaleri, M.; Coenen, S.; Cohen, J.; Findlay, D.; Gyssens, I.; Heure, O.E.; Kahlmeter, G.; Kruse, H.; Laxminarayan, R.; Liébana, E.; López-Cerero, L.; MacGowan, A.; Martins, M.; Rodríguez-Baño, J.; Rolain, J.M.; Segovia, C.; Sigauque, B.; Tacconelli, E.; Wellington, E.; Vila, J. The global threat of antimicrobial resistance: science for intervention. New Microbes and New Infections 2015, 6, 22-29, https://doi.org/10.1016/j.nmni.2015.02.007.

5. Mahmoudi, H.; Bahador, A.; Pourhajibagher, M.; Alikhani, M.Y. Antimicrobial Photodynamic Therapy: An Effective Alternative Approach to Control Bacterial Infections. Journal of Lasers in Medical Sciences 2018, 9, 154-160, https://doi.org/10.15171/jlms.2018.29.

6. Sridharan, G.; Shankar, A.A. Toluidine blue: A review of its chemistry and clinical utility. Journal of oral and maxillofacial pathology: JOMFP 2012, 16, 251, https://doi.org/10.4103/0973-029X.99081.

7. Paul, P.; Mati, S.S.; Bhattacharya, S.C.; Kumar, G.S. Spectroscopic, calorimetric, cyclic voltammetric and molecular modeling studies of new methylene blue-polyadenylic acid interaction and comparison to thionine and toluidine blue O: Understanding self-structure formation by planar dyes. Dyes and Pigments 2017, 136, 205-218, https://doi.org/10.1016/j.dyepig.2016.08.027.

8. George, S.; Hamblin, M.R.; Kishen, A. Uptake pathways of anionic and cationic photosensitizers into bacteria. Photochemical \& Photobiological Sciences 2009, 8, 788-795, https://doi.org/10.1039/b809624d.

9. Dapson, R.W. Dye-tissue interactions: mechanisms, quantification and bonding parameters for dyes used in biological staining. Biotech. Histochem. 2005, 80, 49-72, https://doi.org/10.1080/10520290500219982.

10. Hirakawa, K.; Ishikawa, T. Phenothiazine dyes photosensitize protein damage through electron transfer and singlet oxygen generation. Dyes and Pigments 2017, 142, 183-188, https://doi.org/10.1016/j.dyepig.2017.03.035.

11. Sahu, K.; Bansal, H.; Mukherjee, C.; Sharma, M.; Gupta, P.K. Atomic force microscopic study on morphological alterations induced by photodynamic action of Toluidine Blue O in Staphylococcus aureus and Escherichia coli. J. Photochem. Photobiol. B: Biol. 2009, 96, 9-16, https://doi.org/10.1016/j.jphotobiol.2009.03.008.

12. Brown, S.; Santa Maria Jr, J.P.; Walker, S. Wall teichoic acids of gram-positive bacteria. Annu. Rev. Microbiol. 2013, 67, 313-336, https://doi.org/10.1146/annurev-micro-092412-155620.

13. Neuhaus, FC.; Baddiley, J.; A continuum of anionic charge: structures and functions of D-alanyl-teichoic acids in gram-positive bacteria. Microbiol. Mol. Biol. Rev. 2003, 67, 686, https://doi.org/10.1128/MMBR.67.4.686-723.2003.

14. Wanner, S.; Schade, J.; Keinhörster, D.; Weller, N.; George, S.E.; Kull, L.; Bauer, J.; Grau, T.; Winstel, V.; Stoy, H.; Kretschmer, D.; Kolata, J.; Wolz, C.; Bröker, B.M.; Weidenmaier, C. Wall teichoic acids mediate increased virulence in Staphylococcus aureus. Nature Microbiology 2017, 2, 16257, https://doi.org/10.1038/nmicrobiol.2016.257. 
15. Caudill, E.R.; Hernandez, R.T.; Johnson, K.P.; O'Rourke, J.T.; Zhu, L.; Haynes, C.L.; Feng, Z.V.; Pedersen, J.A. Wall teichoic acids govern cationic gold nanoparticle interaction with Gram-positive bacterial cell walls. Chemical Science 2020, 11, 4106-4118, https://doi.org/10.1039/C9SC05436G.

16. Martínez, B.; Rodríguez, A.; Kulakauskas, S.; Chapot-Chartier, M.-P. Cell wall homeostasis in lactic acid bacteria: threats and defences. FEMS Microbiol. Rev. 2020, 44, 538-564, https://doi.org/10.1093/femsre/fuaa021.

17. Chen, X.; Yan, C.C.; Zhang, X.; Zhang, X.; Dai, F.; Yin, J.; Zhang, Y. Drug-target interaction prediction: databases, web servers and computational models. Brief. Bioinform. 2016, 17, 696-712, https://doi.org/10.1093/bib/bbv066.

18. Mohamed, A.; Fahim, A.M.; Ibrahim, M.A. Theoretical investigation on hydrogen bond interaction between adrenaline and hydrogen sulfide. J. Mol. Model. 2020, 26, 1-13, https://doi.org/10.1007/s00894-020-046022 .

19. El-Mansy, M.A.M.; Osman, O.; Mahmoud, A.A.; Elhaes, H.; Gawad, A.E.A.; Ibrahim, M.A. Computational Notes on the Chemical Stability of Flutamide. Letters in Applied NanoBioScience 2020, 9, 1147-1155.

20. El-Mansy M. A. M.; Osman, O.; Mahmoud, A.; Elhaes H.; Ibrahim, M. Computational Notes on the Molecular Modeling Analyses of Flutamide, Letters in Applied NanoBioScience. 2020, 9, 1099-1102.

21. Assirey, E.A.; Sirry, S.M.; Burkani, H.A.; Ibrahim, M.A. Modified Ziziphus spina-christi stones as green route for the removal of heavy metals. Sci. Rep. 2020, 10, 20557, https://doi.org/10.1038/s41598-020-76810$\mathrm{y}$.

22. Gu, W.; Li, Q.; Li, Y. Environment-friendly PCN derivatives design and environmental behavior simulation based on a multi-activity 3D-QSAR model and molecular dynamics. J. Hazard. Mater. 2020, 393, 122339, https://doi.org/10.1016/j.jhazmat.2020.122339.

23. Bhatt, P.; Pal, K.; Bhandari, G.; Barh, A. Modelling of the methyl halide biodegradation in bacteria and its effect on environmental systems. Pestic. Biochem. Physiol. 2019, 158, 88-100, https://doi.org/10.1016/j.pestbp.2019.04.015.

24. Jan Akhunzada, M.; D’Autilia, F.; Chandramouli, B.; Bhattacharjee, N.; Catte, A.; Di Rienzo, R.; Cardarelli, F.; Brancato, G. Interplay between lipid lateral diffusion, dye concentration and membrane permeability unveiled by a combined spectroscopic and computational study of a model lipid bilayer. Sci. Rep. 2019, 9, 1508, https://doi.org/10.1038/s41598-018-37814-X.

25. de Farias, S.T.; José, M.V. Transfer RNA: The molecular demiurge in the origin of biological systems. Prog. Biophys. Mol. Biol. 2020, 153, 28-34, https://doi.org/10.1016/j.pbiomolbio.2020.02.006.

26. Voicescu, M.; Craciunescu, O.; Angelescu, D.G.; Tatia, R.; Moldovan, L. Spectroscopic, molecular dynamics simulation and biological studies of Flavin MonoNucleotide and Flavin Adenine Dinucleotide in biomimetic systems. Spectrochimica Acta Part A: Molecular and Biomolecular Spectroscopy 2021, 246, 118997, https://doi.org/10.1016/j.saa.2020.118997.

27. Ezzat, H.A.; Hegazy, M.A.; Nada, N.A.; Osman, O.; Ibrahim, M.A. Application of natural polymers enhanced with $\mathrm{ZnO}$ and $\mathrm{CuO}$ as humidity sensor. NRIAG Journal of Astronomy and Geophysics 2020, 9, 586-597, https://doi.org/10.1080/20909977.2020.1821573.

28. Ezzat, H.A.; Hegazy, M.A.; Nada, N.A.; Osman, O.; Ibrahim, M.A. Development of natural polymer/metal oxide nanocomposite reinforced with graphene oxide for optoelectronic applications. NRIAG Journal of Astronomy and Geophysics 2021, 10, 10-22, https://doi.org/10.1080/20909977.2020.1846246.

29. Yu, W.; Shen, G.; Zhang, Y.; Li, D.; Zhou, H. Molecular configuration evolution model and simulation for polymer melts using a non-equilibrium irreversible thermodynamics method. Appl. Math. Model. 2021, 89, 1357-1372, https://doi.org/10.1016/j.apm.2020.07.017.

30. Ming, Y.; Zhou, Z.; Zhang, S.; Wei, Y.; Hao, T.; Nie, Y. Molecular simulation of crystallization of polymers confined in cylindrical nanodomain. Polymer 2020, 206, 122818, https://doi.org/10.1016/j.polymer.2020.122818.

31. Xu, F.; Fang, F.; Zhang, X. Study on surface generation in nano-cutting by large-scale molecular dynamics simulation. The International Journal of Advanced Manufacturing Technology 2019, 104, 4325-4329.

32. Kaviani, S.; Shahab, S.; Sheikhi, M. Adsorption of alprazolam drug on the B12N12 and A112N12 nano-cages for biological applications: A DFT study. Physica E: Low-dimensional Systems and Nanostructures 2021, 126, 114473, https://doi.org/10.1016/j.physe.2020.114473.

33. Yousef, T.A. Structural, optical, morphology characterization and DFT studies of nano sized Cu(II) complexes containing schiff base using green synthesis. J. Mol. Struct. 2020, 1215, 128180, https://doi.org/10.1016/j.molstruc.2020.128180. 
34. Abd El-Kareem, M.S.M.; Rabbih, M.A.; Selim, E.T.M. Semi-Empirical and HOMO, LUMO Studies of Some Chlorinated Pesticides Compounds. Commun. Comput. Chem 2018, 6, 1-12, https://doi.org/10.4208/cicc.2018.v6.n1.1.

35. Xu, Y.; Hou, J.; Ivanov, K.N. Improvement to NEM SP3 Modelling and Simulation. Proc. Of the PHYSOR 2020, Cambridge, United Kingdom. 2020.

36. Brantley, P.S.; Larsen, E.W. The Simplified P3 Approximation. Nucl. Sci. Eng. 2000, 134, 1-21, https://doi.org/10.13182/NSE134-01.

37. ElZorkany, H.E.; Youssef, T.; Mohamed, M.B.; Amin, R.M. Photothermal versus photodynamic treatment for the inactivation of the bacteria Escherichia coli and Bacillus cereus: An in vitro study. Photodiagnosis Photodyn. Ther. 2019, 27, 317-326, https://doi.org/10.1016/j.pdpdt.2019.06.020.

38. Gutiérrez-Fernández, J.; Saleh, M.; Alcorlo, M.; Gómez-Mejía, A.; Pantoja-Uceda, D.; Treviño, M.A.; Voß, F.; Abdullah, M.R.; Galán-Bartual, S.; Seinen, J.; Sánchez-Murcia, P.A.; Gago, F.; Bruix, M.; Hammerschmidt, S.; Hermoso, J.A. Modular Architecture and Unique Teichoic Acid Recognition Features of Choline-Binding Protein L (CbpL) Contributing to Pneumococcal Pathogenesis. Sci. Rep. 2016, 6, 38094, https://doi.org/10.1038/srep38094.

39. Frisch, M.J.; Trucks, G.W.; Schlegel, H.B.; Scuseri, G. E.; Robb, M.A.; Cheeseman, J.R.; Scalmani, G.; Barone, V.; Mennucci , P.B.G.A.; Nakatsuji, H.; Caricato, M.; Li, X.; Hratchian, P.HI.; Izmaylov, A.F.; Bloino, J.; Zheng, G.; Sonnenberg, J.L.; Hada, M.; Ehara, M.; Toyota, K.; Fukuda, R.; Hasegawa, J.; Ishida, M.; Nakajima, T.; Honda, Y.; Kitao, O.; Nakai, H.; Vreven, T.; Montgomery, J.A.; Jr;. Peralta, J.E.; Ogliaro, F.; Bearpark, M.; Heyd, J.J.; Brother, E.; Kudin, K.N.; Staroverov, V.N.; Keith, T.; Kobayashi, R.; Normand, .J, Raghavachari, K.; Rendell, A.; Burant, J.C.; Iyengar, S.S.; Tomasi, J.; Cossi, M.; Rega, N.; Millam, J.M.; Klene, M.; Knox, J.E.; Cross, J.B.; Bakken, V.; Adamo, C.; Jaramillo, J.; Gomperts, R.; Stratmann, R.E.; Yazyev, O.; Austin, A.J.; Cammi, R.; Pomelli, C.; Ochterski, J.W.; Martin, R.L.; Morokuma, K.; Zakrzewski, V.G.; Voth, G.A.; Salvador, P.; Dannenberg, J.J.; Dapprich, S.; Daniels, A.D.; Farkas, O.; Foresman, J.B.; Ortiz, J.V.; Cioslowski, J.; Fox, D.J. Gaussian 09, Revision C.01, Gaussian, Inc.; Wallingford CT 2010

40. Ancın, N.A.; Öztaş, S.G.; Küçükterzi, Ö.; Öztaş, N.A. Theoretical investigation of N-trans-cinnamylidenem-toluidine by DFT method and molecular docking studies. J. Mol. Struct. 2019, 1198, 126868, https://doi.org/10.1016/j.molstruc.2019.07.115.

41. Karnan, M.; Balachandran, V.; Murugan, M. FT-IR, Raman and DFT study of 5-chloro-4-nitro-o-toluidine and NBO analysis with other halogen (Br, F) substitution. J. Mol. Struct. 2013, 1039, 197-206, https://doi.org/10.1016/j.molstruc.2013.01.070.

42. Chinnasami, S.; Manikandan, M.; Chandran, S.; Paulraj, R.; Ramasamy, P. Growth, Hirshfeld surfaces, spectral, quantum chemical calculations, photoconductivity and chemical etching analyses of nonlinear optical p-toluidine p-toluenesulfonate single crystal. Spectrochimica Acta Part A: Molecular and Biomolecular Spectroscopy 2019, 206, 340-349, https://doi.org/10.1016/j.saa.2018.08.015.

43. Lee, J.H.; Kwon, S.H.; Kwon, S.; Cho, M.; Kim, K.H.; Han, T.H.; Lee, S.G. Tunable electronic properties of nitrogen and sulfur doped graphene: Density functional theory approach. Nanomaterials 2019, 9, 268, https://doi.org/10.3390/nano9020268.

44. Huang, M.; Luo, Z.; Zhu, T.; Chen, J.; Zhang, J.Z.; Xia, F. A theoretical study of the substituent effect on reactions of amines, carbon dioxide and ethylene oxide catalyzed by binary ionic liquids. RSC Advances 2017, 7, 51521-51527, https://doi.org/10.1039/C7RA09485J.

45. Uchiyama, S.; Santa, T.; Imai, K. Semi-empirical PM3 calculation reveals the relationship between the fluorescence characteristics of 4,7-disubstituted benzofurazan compounds, the LUMO energy and the dipole moment directed from the 4- to the 7-position. Journal of the Chemical Society, Perkin Transactions 2 1999, 10.1039/A808010K, 569-576, https://doi.org/10.1039/A808010K.

46. Chaitanya, K. Molecular structure, vibrational spectroscopic (FT-IR, FT-Raman), UV-vis spectra, first order hyperpolarizability, NBO analysis, HOMO and LUMO analysis, thermodynamic properties of benzophenone 2,4-dicarboxylic acid by ab initio HF and density functional method. Spectrochimica Acta Part A: Molecular and Biomolecular Spectroscopy 2012, 86, 159-173, https://doi.org/10.1016/j.saa.2011.09.069.

47. Badry, R.; Ibrahim, A.; Gamal, F.; Shehata, D.; Ezzat, H.; Elhaes, H.; Ibrahim, M. Electronic Properties of Polyvinyl Alcohol/TiO2/SiO2 Nanocomposites, Biointerface Research in. Applied. Chemistry, 2020,10, 6427-6435.

48. Ghanadzadeh Gilani, A.; Dezhampanah, H.; Poormohammadi-Ahandani, Z. A comparative spectroscopic study of thiourea effect on the photophysical and molecular association behavior of various phenothiazine 
dyes. Spectrochimica Acta Part A: Molecular and Biomolecular Spectroscopy 2017, 179, 132-143, https://doi.org/10.1016/j.saa.2017.02.015.

49. Luo, Y.; Liu, X.; Yuan, L.; Li, J. Complicated interactions between bio-adsorbents and mycotoxins during mycotoxin adsorption: Current research and future prospects. Trends Food Sci. Technol. 2020, 96, 127-134, https://doi.org/10.1016/j.tifs.2019.12.012.

50. Xiao, J.; Dufrêne, Y.F. Optical and force nanoscopy in microbiology. Nature Microbiology 2016, 1, 16186, https://doi.org/10.1038/nmicrobiol.2016.186. 